\title{
Measurement of the degree of polarisation of thermally modified Scots pine using a Stokes imaging polarimeter
}

\author{
Ilpo Niskanen ${ }^{1,2} \cdot$ Jukka Räty $^{3} \cdot$ Hariyadi Soetedjo ${ }^{4} \cdot$ Kenichi Hibino $^{5} \cdot$ Hiroshi Oohashi $^{6} \cdot$ Rauno Heikkilä $^{1}$. \\ Kiyofumi Matsuda ${ }^{7} \cdot$ Yukitoshi Otani $^{8}$
}

Received: 25 September 2019 / Accepted: 8 December 2019 / Published online: 8 January 2020

(c) The Author(s) 2020

\begin{abstract}
This study measured the polarised light reflected from the surface of thermally modified Scots pine (Pinus sylvestris L.) wood using a Stokes imaging polarimeter. The data were analysed using the Mueller matrix method. The Scots pine boards were heat treated in an oven at temperatures of $160{ }^{\circ} \mathrm{C}, 200^{\circ} \mathrm{C}$ and $220^{\circ} \mathrm{C}$, with a heat treatment time of $3 \mathrm{~h}$ at the maximum temperature. The results indicated that the chemical composition of the thermally modified wood underwent a permanent transformation, leading to a change in the degree of polarisation of the reflected light. The presented method provides useful information for inspecting the quality of thermally modified wood products.
\end{abstract}

Keywords Light polarization method · Heat treatment wood · Degree of polarization (DOP) - Imaging stokes polarimeter · Mueller matrix

\section{Introduction}

Wood is an environmentally friendly, multipurpose material. However, some properties of wood are not optimal, such as its dimensional stability. The characteristics of wood can be modified using different treatment methods, including thermal treatment, which is used to improve its durability, its resistance to mould and decay fungi, its dimensional stability, its weather resistance and its visual appearance [1-4]. In 2017, thermal modification at a typical temperature range of $185-215^{\circ} \mathrm{C}$ was the industrial process that was

Ilpo Niskanen

ilpo.niskanen@oulu.fi

1 Faculty of Technology, Structures and Construction Technology, University of Oulu, P.O. Box 7300, FI-90014 Oulu, Finland

2 Public Works Research Institute, 1-6 Minamihara, Tsukuba, Ibaraki 300-2621, Japan

3 Unit of Measurement Technology (MITY), University of Oulu, Technology Park 127, FI-87400 Kajaani, Finland

4 Center for Integrated Research and Innovation (CIRNOV), University of Ahmad Dahlan, Jalan Cendana No 9A, Semaki, Yogyakarta 55166, Indonesia applied to approximately $200,000 \mathrm{~m}^{3}$ of the sawn timber in Finland (Thermowood $₫ 2017$ production statistics) [5]. The heat treatment process takes about 48-72 h. However, the heat treatment process is different for pine and birch. Increased production volumes have created a practical need for an inexpensive, easy-to-use and rapid analysis method for defining the treatment condition of wood specimens after thermal modification, and to monitor the quality of thermally modified wood available in the marketplace. Traditionally, the quality classification of thermally modified wood is monitored using colour, mass loss and Young's modulus [6].

5 National Institute of Advanced Industrial Science and Technology/Geological Survey of Japan (AIST/GSJ) Central 7, 1-1-Higashi, Tsukuba, Ibaraki 305-8567, Japan

$6 \quad$ National Institute of Advanced Industrial Science and Technology (AIST), AIST Tsukuba East, 1-2-1 Namiki, Tsukuba, Ibaraki 305-8564, Japan

7 Optical Informatio Processing and Systems Engineering Division, The Graduate School for the Creation of New Photonics Industries, 1955-1, Kurematsucho, Nishi-ku, Hamamatsu, Shizuoka 431-1202, Japan

8 Department of Optical Engineering/Center for Optical Research and Education (CORE), Utsunomiya University, 7-1-2, Yoto, Utsunomiya, Tochigi 321-8585, Japan 
Colour information can be used to define various classifications of thermally modified wood (degrees of heat treatment) [7]. Sandak et al. [8] suggested that the Fourier transform near infrared (FT-NIR) spectroscopy technique could be used to control the quality of the final product. Wood mainly consists of hemicelluloses, cellulose and lignins. Hemicelluloses and cellulose are polysaccharides, while lignins are highly complex, mainly aromatic, polymers of phenylpropane units. Wood also contains small amounts of extractives, such as resin, fatty acids, fats, waxes, fatty alcohols, phenols, terpenes and steroids [9]. The crystalline cellulose found in wood contains long-chain polysaccharides composed of $\beta$-1,4-linked D-glucose rings that cause rotation of linearly polarised light, which results from the birefringence of a uniaxial cellulose crystal [10]. The birefringence of thermally modified wood has been investigated by measuring the effective refractive index of wood using the immersion matching method [11]. The disadvantage of the immersion matching method is that measurement requires sample preparation. Moreover, the measurement process takes a long time, and immersion liquids with a high refractive index are typically expensive and toxic. The light polarisation technique has been used to determine the degree of heat treatment of wood based on changes in the birefringence properties of wood [12]. The disadvantage of the light polarisation technique is that determination is based on a small area (diameter of a laser beam) on the board.

This study aimed to investigate the change in the birefringence properties of the thermally modified wood by measuring light reflection with a Stokes imaging polarimeter based on the Mueller matrix method. There are several advantages to using a Stokes imaging polarimeter; the instrument provides high repeatability and accuracy, as well as information about the shape and texture of the reflecting surfaces. The results are also robust, the capture is reusable, and the image provides a visual perception. The polarimeter is comparatively easier use than other instruments, and it provides a large field of view on the sample. However, a Stokes imaging polarimeter is expensive, which is its main disadvantage.

\section{Materials and methods}

The thermal modification of the timber used in this study was performed according to the Thermowood ${ }^{\circledR}$ process [13]. Scots pine (Pinus sylvestris L.) boards samples were modified in a special kiln, which has a capacity of $1 / 2 \mathrm{~m}^{3}$. The boards with dimensions of $63(\mathrm{H}) \times 75(\mathrm{~W}) \times 2000(\mathrm{~L}) \mathrm{mm}$ were treated at $160{ }^{\circ} \mathrm{C}, 200{ }^{\circ} \mathrm{C}$ and $220^{\circ} \mathrm{C}$, with a heat treatment time of $3 \mathrm{~h}$ at the maximum temperature. The boards were sawn from trees that were grown in Central Finland, approximately between $64-65^{\circ} \mathrm{N}$ and $27-28^{\circ} \mathrm{E}$. The boards contained both heartwood and sapwood. After modification, the boards were cut and planed into $4(\mathrm{H}) \times 20(\mathrm{~W}) \times 80(\mathrm{~L})$ $\mathrm{mm}$ samples for the measurement. After the heat treatment process, boards are stabilized to room temperature before measurement. The wood samples were measured in a laboratory that was conditioned at $22{ }^{\circ} \mathrm{C}$ and $75 \%$ relative humidity.

The polarisation state of light can be characterised by four measurable parameters known as the Stokes polarisation parameters. The first parameter, $S_{0}$, expresses the total intensity of the light. The remaining three parameters, $S_{1}$, $\mathrm{s} S_{2}$, and $S_{3}$, describe the polarisation states, which express the intensity of the horizontal linear polarisation, $45^{\circ}$ linear polarisation and right circular polarisation, respectively. These parameters are usually expressed as a column vector known as the Stokes vector [14]. The Stokes vector is a complete representation of the polarisation state. The detection system used in our study consists of a dual rotating speed of a retarder and an analyser at a ratio of 1:3 (as seen in Figs. 1 and 2) [15]. A Prosilica GS1380 charge coupled device
Fig. 1 Experimental setup of the Stokes imaging polarimeter

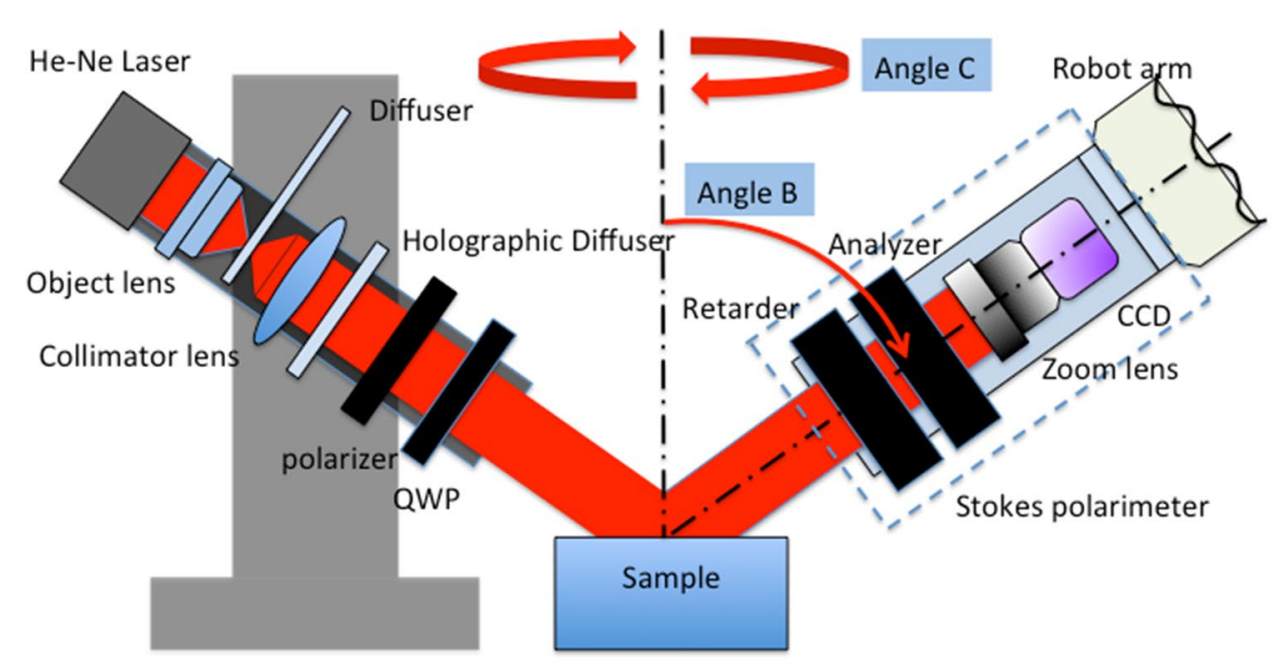




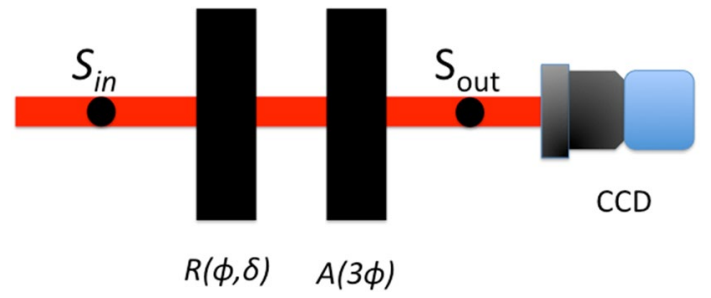

Fig. 2 The rotating retarder and analyser used to analyse the reflected light

(CCD) camera, with a resolution of $1360 \times 1024$ pixels, was used. The wavelength of the light source was $632.8 \mathrm{~nm}$. The measured light can be represented as:

$S_{\text {out }}=A(3 \phi) \cdot R(\phi, \delta) \cdot S_{\text {in }}$,

where $A(3 I(\phi))$ and $R(I(\phi), \delta)$ are indicated as the Mueller matrix of the analyser and the retarder at angle $I(\phi)$ and retardance $\delta$, respectively. $S_{\text {in }}$ and $S_{\text {out }}$ represent the Stokes parameters of the incident and the reflected light, respectively. Using the corresponding Mueller matrix of each element, Eq. (1) can be expressed as:

$\left[\begin{array}{l}S_{0_{\text {out }}} \\ S_{1_{\text {out }}} \\ S_{2_{\text {out }}} \\ S_{3_{\text {out }}}\end{array}\right]=\left[\begin{array}{cccc}1 & \cos 6 \phi & \sin 6 \phi & 0 \\ \cos 6 \phi & \cos ^{2} 6 \phi & \cos 6 \phi \sin 6 \phi & 0 \\ \sin 6 \phi & \cos 6 \phi \sin 6 \phi & \sin ^{2} 6 \phi & 0 \\ 0 & 0 & 0 & 0\end{array}\right]$

$\cdot\left[\begin{array}{cccc}1 & 0 & 0 & 0 \\ 0 & 1-(1-\cos \delta) \sin ^{2} 2 \phi & (1-\cos \delta) \sin 2 \phi \cos 2 \phi & -\sin \delta \sin 2 \phi \\ 0 & (1-\cos \delta) \sin 2 \phi \cos 2 \phi & 1-(1-\cos ) \cos ^{2} 2 \phi & \sin \delta \cos 2 \phi \\ 0 & \sin \delta \sin 2 \phi & -\sin \delta \cos 2 \phi & \cos \delta\end{array}\right]$ $a_{o} / 2=I_{0} / 2 \cdot S_{0_{\text {in }}}$

$a_{2}=I_{0} / 2 \cdot \sin ^{2}(\delta / 2) \cdot S_{1_{\text {in }}}$

$b_{2}=I_{0} / 2 \cdot \sin ^{2}(\delta / 2) \cdot S_{2_{\text {in }}}$

$b_{4}=I_{0} / 2 \cdot \sin ^{2}(\delta / 2) \cdot S_{3_{\text {in }}}$

$a_{6}=I_{0} / 2 \cdot \cos ^{2}(\delta / 2) \cdot S_{1_{\text {in }}}$

$b_{6}=I_{0} / 2 \cdot \cos ^{2}(\delta / 2) \cdot S_{2_{\text {in }}}$.

Taking into account each coefficient, the retardance can be retrieved as:

$\delta=2 \cdot \tan ^{-1}\left(\sqrt{\left(a_{2}-b_{2}\right) /\left(a_{6}+b_{6}\right)}\right)$.

Finally, the Stokes parameter can be written as:

$S=\left[\begin{array}{c}S_{0_{\text {in }}} \\ S_{1_{\text {in }}} \\ S_{2_{\text {in }}} \\ S_{3_{\text {in }}}\end{array}\right]=\left[\begin{array}{c}a_{0} / I_{0} \\ 2 \cdot\left(a_{0}+a_{6}\right) / I_{0} \\ 2 \cdot\left(b_{6}-b_{2}\right) / I_{0} \\ 2 \cdot b_{4} \cdot\left(1 / \sin \delta / I_{0}\right)\end{array}\right]$.

With the Stokes parameters, the degree of polarisation (DOP) is defined as the ratio of the sum of the intensity of

$$
\cdot I_{0}\left[\begin{array}{l}
S_{0_{\text {in }}} \\
S_{1_{\text {in }}} \\
S_{2_{\text {in }}} \\
S_{3_{\text {in }}}
\end{array}\right]
$$

The intensity $I(\phi)$ detected by the CCD camera can be obtained as:

$$
\begin{aligned}
I(\phi)= & \frac{I_{0}}{2} \cdot\left[S_{0_{\text {in }}}+\sin ^{2}(\delta / 2) \cdot S_{1_{\text {in }}} \cdot \cos 2 \phi\right. \\
& +\cos ^{2}(\delta / 2) \cdot S_{1_{\text {in }}} \cdot \cos 6 \phi-\sin ^{2}(\delta / 2) \cdot S_{2_{\text {in }}} \cdot \sin 2 \phi \\
& \left.+\sin \delta \cdot S_{3_{\text {in }}} \cdot \sin 4 \phi+\cos ^{2}(\delta / 2) \cdot S_{2_{\mathrm{s}}} \cdot \sin 6 \phi\right]
\end{aligned}
$$

By analysing the Fourier transform of the intensity, its corresponding coefficients can be obtained as: the polarised light to the total intensity. Then DOP can be expressed as:

$\mathrm{DOP}=\frac{\sqrt{s_{1}^{2}+s_{2}^{2}+s_{3}^{2}}}{s_{0}},(0 \leq \mathrm{DOP} \leq 1)$.

Crystalline materials are often utilised, especially in the field of optics, due to their ability to modify light. Often these materials divide a light beam into two beams; thus, the material is referred to as being optically birefringent. 

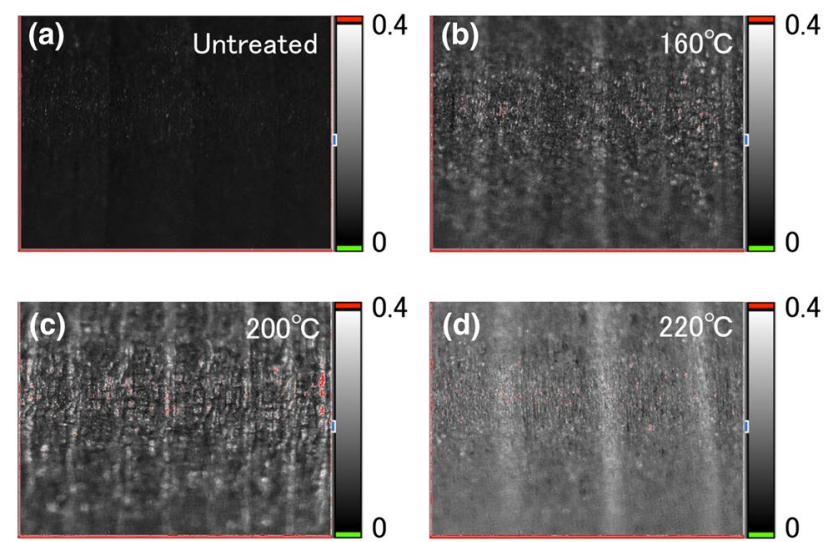

Fig. 3 Stokes image (DOP) of Scots pine wood: a untreated; $\mathbf{b}$ treatment at $160{ }^{\circ} \mathrm{C} ; \mathbf{c}$ treatment at $200{ }^{\circ} \mathrm{C} ; \mathbf{d}$ treatment at $220^{\circ} \mathrm{C}$

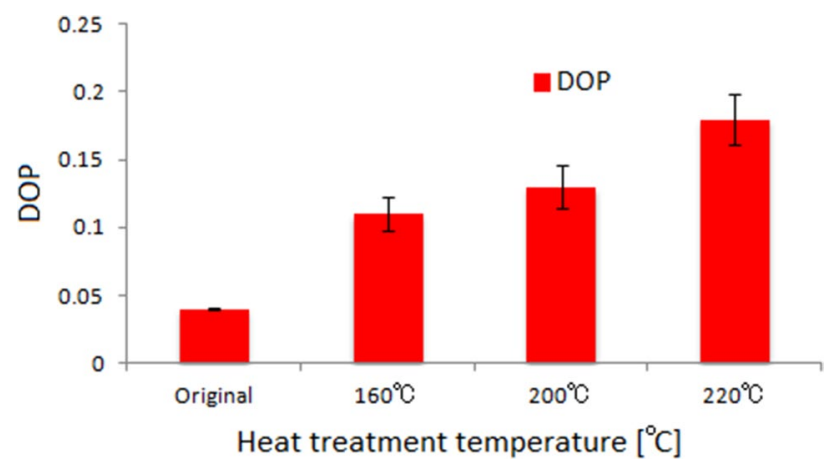

Fig. 4 Average DOP value of untreated and thermally modified pine as a function of temperature. The line segments display standard deviations of the measurements $(n=6)$

Birefringence generates and alters light polarisation. The state of polarised light is measured by the DOP $(\mathrm{DOP}=1$ for perfectly polarised light and $\mathrm{DOP}=0$ for unpolarised light). At the microscopic scale, native untreated timber also contains crystalline structures. Here, it is assumed that the heat treatment alters/destroys the crystalline structures; consequently, the polarisation properties (e.g., the DOP) of the polarised light that interacts with the wood changes. We have developed calculations using the LabView program to reconstruct the two-dimensional intensity images as well as the corresponding Stokes vector and the different polarisation parameter images.

\section{Results and discussion}

The DOP values, as a function of temperature for the untreated and thermally modified Scots pine samples, are presented in Figs. 3 and 4. Figure 4 shows the mean values of the images shown in Fig. 3. However, the outer borders (width: 10 pixels) of each image were removed while calculating the mean value to reduce error. In Fig. 3, the light and dark stripes represent the annual growth rings. The density of the summer wood (the wider, darker stripes seen in Fig. 4) is higher than the density of the spring wood (thinner, lighter stripes). Moreover, the summer wood has a higher concentration of cellulose than the spring wood. Due to its crystalline nature, cellulose is less affected by the heat treatment process. This is shown in Fig. 4 as a darker stripe. Furthermore, as seen in Figs. 3 and 4, the DOP of light increases when the treatment temperature increases. This could be because the wood fibre loses its birefringence property. Also, the age of the wood can affect the softwood to the heartwood ratio. The temperature and treatment time influence differently heartwood and softwood such as weight loss. Heartwood is almost always darker as the softwood after the heat-treatment process. In addition, pine heartwood generally contains significantly more wood protecting compounds than pine softwood, which is why pine heartwood decay resistance is better. The ordinary and extraordinary refractive indices of crystalline cellulose are 1.5956 and 1.5312 , respectively; thus, the birefringence is +0.0644 at a wavelength of $589 \mathrm{~nm}$ [16]. Niskanen et al. [11] determined the refractive indices of thermally modified Scots pine using the immersion liquid technique in untreated samples and samples treated at $180^{\circ} \mathrm{C}, 200{ }^{\circ} \mathrm{C}$ and $230{ }^{\circ} \mathrm{C}$, resulting in refractive index values of $1.553,1.557,1.587$ and 1.596 , respectively. The refractive index of thermally $\left(230^{\circ} \mathrm{C}\right)$ modified Scots pine approaches the maximum ordinary refractive index of cellulose, which is 1.596 . Therefore, the birefringence property of wood can disappear at a high temperature. A similar result was reported by Deguchi et al. [17]; that study investigated the birefringence property of cellulose in water at a temperature around $320^{\circ} \mathrm{C}$ and a constant pressure of $25 \mathrm{MPa}$.

\section{Conclusion}

Heat treatment causes changes to occur in the crystalline structure of cellulose. That can be observed by measuring the DOP using Stokes imaging polarimeter analysis. There are several major advantages to using a Stokes imaging polarimeter. The method is sensitive, it provides a large field of view on the sample, the capture image is reusable, the image provides a visual perception and it is possible to conduct a non-contact analysis of the samples. We believe that a Stokes imaging polarimeter is a useful tool for conducting a quality inspection of thermally modified wood. Understanding the changes in the optical properties of cellulose is an important step in developing better control systems for the thermal treatment process. 
Acknowledgement Open access funding provided by University of Oulu including Oulu University Hospital.

Open Access This article is licensed under a Creative Commons Attribution 4.0 International License, which permits use, sharing, adaptation, distribution and reproduction in any medium or format, as long as you give appropriate credit to the original author(s) and the source, provide a link to the Creative Commons licence, and indicate if changes were made. The images or other third party material in this article are included in the article's Creative Commons licence, unless indicated otherwise in a credit line to the material. If material is not included in the article's Creative Commons licence and your intended use is not permitted by statutory regulation or exceeds the permitted use, you will need to obtain permission directly from the copyright holder. To view a copy of this licence, visit http://creativecommons.org/licenses/by/4.0/.

\section{References}

1. Romagnoli, M., Vinciguerra, V., Silvestri, A.: Heat treatment effect on lignin and carbohydrates in corsican pine earlywood and latewood studied by PY-GC-MS technique. J. Wood Chem. Technol. 38(1), 57-70 (2018)

2. Uribe, B.E.B., Ayala, A.: Characterization of three wood species (Oak, Teak and Chanul) before and after heat treatment. J Indian Acad. Wood Sci. 12(1), 54-62 (2015)

3. Hill, C.A.S.: Wood Modification: Chemical, Thermal and Other Processes. Wiley, Chichester (2006)

4. Heräjärvi, H.: Effect of drying technology on aspen wood properties. Silva Fenn. 43(3), 433-445 (2009)

5. Thermowood ${ }^{\circledR}$ production statistics (2016) International Thermowood ${ }^{\circledR}$ Association. https://asiakas.kotisivukone.com/files /en.thermowood.palvelee.fi/uutiset/Productionstatistics2016.pdf, (2016). Accessed 15 Jan 2019

6. Esteves, B., Pereira, H.: Wood modification by heat treatment: a review. BioResources 4(1), 370-404 (2009)
7. Schnabel, T., Zimmer, B., Petutschnigg, A.J., Schönberger, S.: An approach to classify thermally modified hardwoods by color. For. Prod. J. 57(9), 106-110 (2007)

8. Sandak, A., Sandak, J., Allegretti, O.: Quality control of vacuum thermally modified wood with near infrared spectroscopy. Vaccum. 114, 44-48 (2015)

9. Rowell, R.M.: Handbook of Wood Chemistry and Wood Composites. CRC Press, Boca Raton (2005)

10. Granston, E.D., Gray, D.G.: Birefringence in spin-coated films containing cellulose nanocrystals. Colloid Surf. A 325, 44-51 (2008)

11. Niskanen, I., Heikkinen, J., Mikkonen, J., Harju, A., Heräjärvi, H., Venäläinen, M., Peiponen, K.-E.: Detection of the effective refractive index of thermally modified Scots pine by immersion liquid method. J. Wood Sci. 65, 46-50 (2012)

12. Soetedjo, H., Niskanen, I.I., Rautkari, L., Altgen, M., Hiltunen, E., Thungström, G., Zakrisson, G.D., Räty, D.J.: Determining the degree of heat treatment of the wood by light polarization technique. Eur. J. Wood Wood Prod. 76, 1359-1362 (2018)

13. ThermoWood Handbook. Finnish Thermowood Association, Helsinki, (2003)

14. Ginya, M., Mizutani, Y., Iwata, T., Otani, Y.: Polarization properties of PLZT ferroelectric ceramics observed in two dimensional distributions under applied voltage by the Mueller matrix. Sens. Actuators A 200, 37-43 (2013)

15. Tanaka, M., Chujo, M., Otani, Y.: Spectroscopic stokes polarimeter with dual rotation retarder and analyzer for LCD evaluation. Kogaku 40(8), 430-438 (2011)

16. Winchell, A.N.: The Optical Properties of Organic Compounds, 2nd edn. Academic Press, Chicago (1987)

17. Deguchi, S., Tsujii, K., Horikoshi, K.: Cooking cellulose in hot and compressed water. Chem. Commun. 31, 3293-3295 (2006)

Publisher's Note Springer Nature remains neutral with regard to jurisdictional claims in published maps and institutional affiliations. 